News

\title{
Congenital heart disease and echocardiography
}

\author{
Volume 3 Issue 5 - 2015
}

\section{News}

The field of pediatric cardiology is currently undergoing great technological change, sadly, today in every 1000 births there are 9 babies born with some form of congenital heart disease. Further, these defects are often complex and require several surgeries and a lifetime of medical follow up. Today, the capability to image these defects in pre surgical, as well as, both during and immediately after the operation is enhanced tenfold by echocardiography.

The dynamic field of cardiac ultrasound is instrumental in both treating and diagnosing congenital heart disease. Two fairly recent developments have been the introduction of $3 \mathrm{D}$ and $4 \mathrm{D}$ echo to help treat congenital heart disease. These technologies allow precise orthogonal imaging planes of the human heart. Conventional ultrasound only images in two standard imaging planes which is not acceptable for complex congenital repairs.

A fairly new field in cardiovascular ultrasound has recently arrived on the scene to help in diagnosing congenital heart disease before the baby is even born. Fetal echocardiography allows the experienced operator to visualize the unborn baby heart which can be beneficial if surgery will be needed when the baby is born.

Future relevant developments could center around hologram ultrasound and $3 \mathrm{D}$ printers which can make heart valves, patches, etc.

\author{
Phillip Louis D`Amato \\ Pediatric Cardiac Sonographer, SRMC University, USA
}

Correspondence: Phillip Louis D 'Amato, Pediatric Cardiac Sonographer \& Founder New Horizons Investments, SRMC University, 7018 packhouse drive Hope Mills, North Carolina, 28348, USA, Tel 910 33965 I8, Email rudy70@hotmail.com

Received: October 20, 2015 | Published: October 23, 2015

\section{Conflicts of interest}

Author declares there are no conflicts of interest.

\section{Funding}

None.

\section{Acknowledgments}

None. 